\title{
Stem Cell Therapy in the Treatment of Neurological Diseases
}

\author{
Murat Kocaoglu ${ }^{1}$, Mustafa Korucu ${ }^{1}$, Serkan Civlan ${ }^{1}$, Kevser Ozdemir $^{2}$, Mevci Ozdemir $^{{ }^{*}}$ and Bayram Cırak ${ }^{1}$ \\ ${ }^{1}$ Pamukkale University, Faculty of Medicine, Department of Neurosurgery, Denizli, Turkey \\ ${ }^{2}$ Denizli State Hospital, Department of Infectious Diseases and Clinical Microbiology, Denizli, Turkey
}

*Corresponding author: Mevci Ozdemir, Associate Professor, Pamukkale University, Faculty of Medicine, Department of Neurosurgery, 20070, Kinikli, Denizli, Turkey, Tel: +90 258444 0728; Fax: +90 258213 4922; E-mail: drmevci@hotmail.com

Received date: May 22, 2014, Accepted date: June 23, 2014, Published date: June 30, 2014

Copyright: (c) 2014 Kocaoglu M, et al. This is an open-access article distributed under the terms of the Creative Commons Attribution License, which permits unrestricted use, distribution, and reproduction in any medium, provided the original author and source are credited.

\begin{abstract}
Before a half century, regeneration of neurons has been admitted as an impossible event. Thus, neurodegenerative disorders (e.g. Parkinson's disease, Alzheimer's disease, multiple sclerosis), vascular events (e.g. stroke) and traumatic diseases (e.g. spinal cord injury) have been admitted as incurable diseases. Afterward, tissue reparative and regenerative potential of stem cell researches for these disorders drew attention of the scientist to replacement therapy. Now, there are hundreds of current experimental and clinical regenerative treatment studies. One of the most popular treatment methods is cell transplantation. For this purpose many types of stem cells such as mononuclear stem cells, mesenchymal stem cells, and olfactory ensheathing cells can be used. As a result, cell transplantation has become a promising therapeutic option for these neurologic disorders. In this article, we reviewed stem cell treatment modalities for neurological disorders in the light of current literature.
\end{abstract}

Keywords: Stem cell; Spinal cord injury; Regeneration; Parkinson's disease; Amyotrophic lateral sclerosis; Stroke

\section{Introduction}

Until the middle of the $20^{\text {th }}$ century, regeneration of nerve tissue was considered to be impossible, however, nowadays in many studies especially developments in stem cells technology showed that new neurons can be obtained from different stem cells. For this reason, a glimmer of hope was emerged for some neurotraumatic and neurodegenerative disease such as spinal cord injury, Parkinson's disease (PD), Huntington's disease (HD), Alzheimer's disease (AD), and amytrophic lateral sclerosis (ALS). In this article, we will provide current information about neurological disorders associated with the use of stem cells.

Stem cells are those cells that have the ability to continuously divide and differentiate into various other kinds of cells and tissues [1]. There are three types of stem cells based on the differentiation potential; Totipotent cell has the power to create an organism alone, pluripotent cells can be converted into all cell types, and multipotent cells can be converted into cell types in their own tissues [2,3]. If we look for origin of stem cells, we can mentioned three types as embryonal, fetal and adult stem cells [4]. For using neurological trial, neurons and glial cells have been generated from stem cells as embryonic stem cells (ESCs), induced pluripotent stem cells (iPSCs), mesenchymal stem cells (MSCs) and neural stem cells (NSCs). ESCs are one of pluripotent stem cells derived from a blastocyst. iPSCs are reprogrammed from adult somatic cells, this genetic reprogramming process can be made with various agents (viral agents, epigenetic factors or plasmid). MSCs display pluripotent characteristic and can different ectomesenchymal derivatives, including not only smooth muscle or endothelium but also neurons and glial cells [5]. Contrary to them, NSCs are multipotent cells that generate into neurons, astrocytes and oligodendrocytes [6].

\section{A Brief History}

The presence of blood cells that can renew themselves was shown for the first time in the 1950s. The definition of stem cells that we use today is built on conducted studies in experimental animals in 1961. With the success of bone marrow transplants, it came up that only the basic cell transplant without the bone marrow in the 1970s. Starting from this date, stem cell transplantations increasingly more began to be implemented and stem cells first used only for the repair of bone marrow, have been introduced to though for other organs and tissues. Embryological origin stem cells were identified in 1998, after then, embryonic germ cells are obtained from human primordial germ cells [7]. iPSCs has initially produced by Shinya Yamanaka at Kyoto University in 2006 [8]. In It has created quite excitement that these stem cells can be used to treat diseases in the future.

\section{Usage of Stem Cells in Neurological Diseases}

Neurological diseases are caused by a loss of neurons and glial cells in the central nervous system (CNS) or peripheral nervous system. Effective treatment of these neurological diseases is currently impossible. Stem cell therapy is a promising treatment option for these neurological diseases [2,9].

\section{Spinal cord injury}

Traumatic spinal cord injuries are one of the challenging problems all around the world. Spinal cord is the main circuit, which transfers motor and sensorial signals between brain and body. After major spinal cord injury, ascending and descending neural systems lost their integrity with motor and sensorial structures in spinal cord and paralysis and anesthesia occur under lesion site [10]. With this type central nervous system injury, serious cell losses in tissues occur, significant myelin loss is seen and it becomes almost impossible to repair neural connections. So it is not possible to gain appropriate results with only decompression and physiotherapy/rehabilitation. On 
the other hand, it has been shown that transplanted hematopoietic stem cells gained from bone marrow regenerate injured cells and repair myelin sheath [11-21]. Spinal cord regeneration was tested in cell cultures and animal experiments firstly. To induce regeneration of injured spinal cord, some methods like reducing scar size, Xirradiation, electrical stimulation, neurotropic factors, grafting, omentum transplantation, and neutralization of neurite growth inhibitors were tested. In recent years, transplanting cells like Schwann cells, olfactory glial cells, embryologic or adult stem cells have become popular and all this methods are named as cell therapy. As a result of these animal experiments, ideal cell type to transplant in spinal cord injuries is not known but strong evidences shows us that site-specific neural progenitor stem cells have to be $[12,14,15]$. McDonalds et al. showed that, neural differentiated mice embryogenic stem cells transplanted to rat spinal cord could stay alive 9 days after traumatic spinal cord injury and these cells' differentiation to astrocyte, oligodendrocyte and neurons [13].

In recent years, it is advised also to use especially cytokine to improve regeneration. Parr and Tator have used cytokine GM-CSF with MSC for regeneration of spinal cord. The mechanism of this protocol is not known exactly but quite good clinical results have been seen and factors that may affect mechanism of action are thought as below; a. Transdifferentiation to injured neural tissues, transformation to neurons, astrocytes and oligodendrocytes, b. Neural protection; Decreasing apoptosis, inflammation, demyelinization and increasing astrocyte survival c. Creating ideal media for regeneration; Proliferation of endogen neural progenitors and oligodendrocytes, forming intercellular bridges, increasing intercellular communication of astrocytes, decreasing glial scar thickness and increasing fibronectin production that prevents glial scar, d. MSC or expression of growth factor or cytokine by host; BDNF, NGF, FGF 2 VEGF, TGF- $\beta$, IGF-1, BNP, SCF 1 e. Vascular effects; Regulation of blood flow, repairing blood-brain barrier, reducing edema, reducing increased intracranial or intraspinal pressure and improving angiogenesis, f. Remyelinization by MSC or host cell, oligodendrocytes, Schwann cells, g. Increasing cell fusion [20]. As a conclusion the actual repair of the spinal cord was being thought as impossible a few years ago. Today, although still cure is not found; but animal and latest human experiments and researches are promising. Recently discovered methods that facilitate axonal regeneration such as transplantation, bridging, and application of exogenous growth factors and also presence of stem cells, which can migrate and proliferate in the adult spinal cord, makes clear and significant improvement in neurological function achievable after spinal cord injury. Based on the results of the present experiments, the possibility of effective regenerative treatment of human spinal cord injury is a realistic goal, not speculation.

\section{Stroke}

Stroke is the most important cause of adult disability in developed and developing countries [22,23]. With the increase in the elderly population, the incidence and prevalence is increasing with each passing day [24]. Central nervous system contains more than 100 billion cells. There are also more than 10,000 subtypes of these cells. These cells communicate with each other by links that are almost too numerous to count. All kinds of cells found in the brain may be affected in stroke and also their connections may be [25]. Until recently, it was considered that there can be no regeneration in the brain of adults. Researches made in the past 10-15 years have showed that neurons and astrocytes can be regenerated from adult mammalian cells [26]. As a result of the highly developed ability of stem cells to transform into neurons, astrocytes and oligodendrocytes, their usage is promising. The aim is starting of the repair process by stimulating the repair function. Thus, neurogenesis, angiogenesis and synaptogenesis is required to be stimulated. In preclinical studies, it has been shown that stem cells stimulate endogenous repair mechanisms and also increase the vascularization of the damaged area. Bone marrowderived mesenchymal stem cells are utilized effectively in the treatment of stroke. In preclinical studies with mesenchymal cells, it is clarified that administration of these cells intracerebral, intraarterial and intravenous ways is possible and functional improvement with all may be provided [27-31]. The resulting functional gains in good directions are due to endogenous trophic effects of stem cells and their stimulation of repair processes more than development of new cells [32]. Among many stem cell mobilizing agents, granulocyte-colony stimulating factor (G-CSF) is particularly come to the fore. Which was approved by the FDA, with the administration of G-CSF, stem cells mobilize from the bone marrow to peripheral blood and may show corrective or protective actions in brain. In addition, G-CSF has neuroprotective effects as well in addition to the known antiinflammatory and angiogenesis properties. An experimental study of the middle cerebral artery occlusion and stroke in mice, when administered within 30 minutes G-CSF has been shown to reduce the infarct area by $47 \%$ [33]. Intracerebrally given peripheral blood stem cells have been demonstrated to enhance neuroplasticity by creating angiogenesis with beta-1 integrin [34]. In many studies of stem cell transplantation after stroke, significant contribution to neurological recovery has been shown both clinically and histopathologically [35].

\section{Parkinson's disease}

Parkinson's disease a progressive neurodegenerative disease characterized by rigidity, tremor and bradykinesia and associated with in loss of function of dopaminergic neurons in the substantia nigra. Prevalence studies show that PD affects over $1 \%$ of the population over the age of 60 [36,37].

There are many different treatment methods of PD. L-DOPA is still fundamental drug in early periods of $\mathrm{PD}$, dopaminergic agonists, rasagiline use in initial treatment for the disease, Catechol-Omethyltransferase inhibitors are effective with motor fluctuations. Apomorphine is another drug that can be used non-oral. Deep brain stimulation is also a widely used treatment method [38]. None of this treatment provides a cure for PD. Moreover, although their effects decrease, side effects are emerging but stem cell therapy would induce long-term clinical improvement [39].

Fetal mesencephalic tissue replacement studies were being performed since 1987 in order to increase dopaminergic neuron level in striatum [39,40]. Until todays, in human, dopaminergic cell transplantation was performed more than 300 cases in Parkinson's disease. The implants adapted with tissue and their continued viability has been proven with PET-scan and clinical improvement $[41,42]$. Embryonic stem cells (ESCs) also had been source for cell replacement therapy in PD. Kim et al. encouraged us about ESC replacement due to renewal ability and pluripotent nature of ESCs [43]. In addition to pluripotent stem cells, adult stem cells have been used as a source for cell replacement therapy, for example MSCs. Although MSCs are obtained bone, muscle tissue, maxillary tissue, dental pulp, liver, placenta, amniotic fluid, cord blood and synovial fluid, even mainly derived from the bone marrow [44]. With the reprogramming methods, scientist can convert fibroblast or other types of somatic cells into neural precursors. Werning at al. have derived DA neurons from 
iPSCs and observed improvement in rodent model of PD after engrafting iPSCs [2].

Furthermore, continue testing with different cells except ESCs, MSC or iPSCs, Murrell et al. were generated dopaminergic neurons from olfactory mucosa in vitro and transplanted to hemiparkinsonian rat model [45]. Olfactory neuroepithelial cells have some advantage as a source of stem cell for example, easy biopsy, regenerative capability, neurogenic differentiation potential; so, scientists may be mostly want to use olfactory neuroepithelial cells in future.

\section{Amyotrophic lateral sclerosis}

Amyotrophic lateral sclerosis; associated with the common upper and lower motor neuron degeneration, generally resulting in death due to respiratory failure an average of three years after the beginning of symptoms [46]. Microglial activation, astrocytosis, lymphocyte infiltration and dendritic cells are accompanied with progressive degeneration of motor neurons [47]. Cause of the disease is not known but glutamate excitotoxicity and oxidative stress, viral infections, autoimmune mechanisms, glial abnormal activity and reduction in trophic factor hypothesis are involved in etiopathogenesis [48].

Definitive diagnosis of ALS is usually confirmed after a period of 1-2 years from the start of symptoms. Riluzole is a glutamate antagonist and the only known treatment of the disease. About $20 \%$ of life was found to be prolonged in patients using this drug [46]. With other agents around 20 clinical studies have been conducted to date. Although some molecules results with promising studies in animal, however, riluzole is the only therapeutic drug approved for ALS with regard to prolonging survival time [49].

Stem cell therapy is one of the treatment methods in order to stop the progression of the disease and if possible return loss of function. It is not a realistic expectation that stem cells integrate to neural network by replacing lost motor neurons. The hope is the halting of motor neuronal death [9]. Stem cell transplantation studies have been shown to be effective in animal. The studies continue about how stem cell effects in ALS [50]. Stem Cell therapies for ALS utilize various types of stem cells to regenerating neurons and support surrounding cells through release of neurotrophic factors, and study disease physiology. Different sources of stem cells include bone marrow, neural stem cells, mesenchymal stem cells, astrocyte precursor cells, and induced pluripotent stem cells [51]. Autologous MSCs were isolated from bone marrow and most of cell-based clinical trials for ALS are based on the use of MSCs. Mazzini et al. has placed the autologous bone marrowderived hematopoietic cells into the spinal cord at TH7-TH9 level for 7 patients. They have showed that in patients with significant gains in the three-year follow-up results and reported that direct injection of autologous MSCs into the spinal cord in ALS patients is a safe method which does not show significant acute or chronic toxicity and is well tolerated [52].

Dimos et al. have generated iPSCs from an ALS patient. These patient-specific iPSCs have properties of embryonic stem cells and were able to differentiate into motor neurons [53].

There are currently ongoing trials of various types of stem cell transplantation (for e.g. Olfactory ensheathing cell, human neural stem cell transplantation) in the USA, Italy, Spain, Canada, Israel and China (for more information www.clinicaltrials.gov). Overall, these trials provide important data about the safety and feasibility of cellbased therapies in ALS patients.

\section{Multiple sclerosis}

Multiple sclerosis (MS); It is an autoimmune central nervous system disease characterized with inflammation, demyelinization and axone injury. In MS pathogenesis; the existence of abnormal immune response against the myelin antigens in CNS is considered. Young women suffer from the disease more frequently [54,55]. Its prevalence varies between 2 to 200 in 100.000 depending on the geographical features. Around $15 \%$ of multiple sclerosis patients have another family member who has been influenced by the disease [56]. Multiple sclerosis is a chronic disease whose one part proceeds with the attacks and the other part proceeds progressively. The most frequent symptoms are motor symptoms, prostration, vision loss, brain stem symptoms, cerebellar symptoms, cognitive disorders; bladder, intestine and sexual disorders [54,55,57].

Nowadays, there is no pathognomonic reagent that can be used for the diagnosis of multiple sclerosis. The diagnosis relies on supporting the clinical symptoms with the laboratory data [56]. The diagnosis of the disease constitutes the Mc Donald criteria, which is widely accepted by an international panel. Two clinical attacks and two lesions have been regarded as the proof for the spread of the disease in time and space, which also forms the main principle of MS diagnosis [58]. The publications about the use of stem cell in MS disease treatment are commonly available in literature and the number of them increases gradually. In literature, there are vast series that constitutes hundreds of symptoms [59-61]. Autologous hematopoietic stem cell transplantation (HSCT) treatment effect can be summarized as the re-programming of the immune system. Supposing that retraining the immune system cells can also prevent the possible MS attacks, it has been attempted in MS disease. In addition, there are also forms that allogenic HSCT applications and MSCS are used. It is striking that in MS disease, nowadays; the stem cell applications in the form of transplantations mainly focus on the oligodendrocyte progenitor cells (OPG). In this approach, the goal is to let the transplanted cells to acquire the capability of forming new myelin, replace the damaged myelin and overtake the functions of healthy myelin and in this way prevent axone destruction. Therefore, in literature, the stem cells are advised for the diseases showing demyelinization such as MS, not only because they have strong antiinflammatory effects but also they have direct repairing effects on the remyelinization and they are more commonly used in time [62,63]. Together with the transplantation, OPG or undifferentiated stem cells can manage to have the components that will protect the tissue. Thus, making a neuroprotective effect on the CNS tissue, which is being damaged due to the ongoing disease activity, has a crucial role in the application of treatment. The stem cells provide trophic recover, and by stimulating endogenic neurons, astrocytes and veins, they let the growth factors to be released and provide multi faceted recovery. It is impossible to say that the stem cells form recovery only by changing into neurons in the complex neural system. Thus, the stem cells will certainly be used more commonly in the neurological diseases in the future [64].

\section{Other neurological diseases}

Congenital metabolic diseases are a vast diagnosis group, which constitutes genetic diseases including metabolism disorders. It is a vast group including carbohydrate metabolism disorders, amino acid metabolism disorders, organic acid metabolism disorders, fatty acid oxidation and mitochondrial metabolism disorders, porphyrine metabolism disorders, purine or pyrimidine metabolism disorders, 
steroid metabolism disorders, mitochondrial malfunction, peroxisomal malfunction, lysosomal storage disorder. Most of them stem from the single gene mistakes encoding the enzymes, which facilitate a substance's conversion into another substance. In most disorders, the troubles are caused by the accumulation of toxic substances or the substance's reduced functions for the normal procedure due to inability of synthesizing. Congenital metabolic diseases are progressive and fatal, so they do not have a distinct and efficient treatment. The strategy of the treatment is to put back the enzymes that have to be in the central neural system. In 2004, Krivit stated that allogenic hematopoietic stem cells were used for the patients with lysosomal storage disease and leukodystrophy [65]. The results are rather satisfactory. Similarly, successful stem cell applications on people with Krabbe's disease have been reported [65]. The reason why stem cells are beneficial in these types of diseases is that the stem cells penetrated into the brain accompany the infiltration of microglial cells and their consequent help to replace the lost enzymes.

When the literature is examined, the stem cell applications for many neurological diseases are increasingly taking place as an alternative treatment method. Intracranial trauma, Alzheimer disease, Huntington's chorea and even the treatment of epilepsy can be accepted among the possible diseases stem cell applications will be used onwards [66-72].

In conclusion, it is quite difficult to treat and cure of neurological diseases because of limited neuron regeneration. Unfortunately, current treatments cannot provide effective solutions to regenerate neurons, at the same time cannot prevent loss of neurons. So, neural stem cell therapies have caused quite a stir with hope to treatment of neurodegenerative disorders. Todays, selection, generation and transplantation of stem cell, all of these major challenges but in the very near future we can say hopefully that stem cell therapies can be applied effectively. In light of these findings, stem cell treatment is a cell substitution for the destroyed spinal cord or CNS, axon regeneration and/or application of a neurotrophic factor to recover the neural tissue. These data are promising, but future studies must continue to establish whether stem cells can serve as a safe and functional autologous source for treatment of the neurological disorders.

\section{References}

1. Paspala SA, Balaji AB, Nyamath P, Ahmed KS, Khan AA, et al. (2009) Neural stem cells \& supporting cells--the new therapeutic tools for the treatment of spinal cord injury. Indian J Med Res 130: 379-391.

2. Yoo J, Kim HS, Hwang DY (2013) Stem cells as promising therapeutic options for neurological disorders. J Cell Biochem 114: 743-753.

3. Pelton TA, Sharma S, Schulz TC, Rathjen J, Rathjen PD (2002) Transient pluripotent cell populations during primitive ectoderm formation: correlation of in vivo and in vitro pluripotent cell development. J Cell Sci 115: 329-339.

4. Takahashi K, Yasuhara T, Shingo T, Muraoka K, Kameda M, et al. ( 2008) Embryonic neural stem cells transplanted in middle cerebral artery occlusion model of rats demonstrated potent therapeutic effects, compared to adult neural stem cells. Brain Res 1234: 172-182.

5. Drela K, Siedlecka P, Sarnowska A, Domanska-Janik K (2013) Human mesenchymal stem cells in the treatment of neurological diseases. Acta Neurobiol Exp (Wars) 73: 38-56.

6. Kim SU, Lee HJ, Kim YB (2013) Neural stem cell-based treatment for neurodegenerative diseases. Neuropathology 33: 491-504.
7. van der Heyden MA, Hescheler J, Mummery CL (2003) Spotlight on stem cells--makes old hearts fresh. Cardiovasc Res 58: 241-245.

8. Yamanaka S, Takahashi K (2006) [Induction of pluripotent stem cells from mouse fibroblast cultures]. Tanpakushitsu Kakusan Koso 51: 2346-2351.

9. Kim SU, de Vellis J (2009) Stem cell-based cell therapy in neurological diseases: a review. J Neurosci Res 87: 2183-2200.

10. Ozdemir M, Attar A, Kuzu I, Ayten M, Ozgencil E, et al. (2012) Stem cell therapy in spinal cord injury: in vivo and postmortem tracking of bone marrow mononuclear or mesenchymal stem cells. Stem Cell Rev 8: 953-962.

11. Bareyre FM (2008) Neuronal repair and replacement in spinal cord injury. J Neurol Sci 265: 63-72.

12. Féron F, Perry C, Cochrane J, Licina P, Nowitzke A, et al. (2005) Autologous olfactory ensheathing cell transplantation in human spinal cord injury. Brain 128: 2951-2960.

13. McDonald JW, Liu XZ, Qu Y, Liu S, Mickey SK, et al. (1999) Transplanted embryonic stem cells survive, differentiate and promote recovery in injured rat spinal cord. Nat Med 5: 1410-1412.

14. Knoller N, Auerbach G, Fulga V, Zelig G, Attias J, et al. (2005) Clinical experience using incubated autologous macrophages as a treatment for complete spinal cord injury: phase I study results. J Neurosurg Spine 3: 173-181.

15. Park HC, Shim YS, Ha Y, Yoon SH, Park SR, et al. (2005) Treatment of Complete spinal cord injury patients by autologous bone marrow cell transplantation and administration of Granulocyte-Macrophage colony stimulating factor. Tissuee Engineering 11: 5-6.

16. Lewis KE (2006) How do genes regulate simple behaviours? Understanding how different neurons in the vertebrate spinal cord are genetically specified. Philos Trans R Soc Lond B Biol Sci 361: 45-66.

17. Ohori Y, Yamamoto S, Nagao M, Sugimori M, Yamamoto N, et al. (2006) Growth factor treatment and genetic manipulation stimulate neurogenesis and oligodendrogenesis by endogenous neural progenitors in the injured adult spinal cord. J Neurosci 26: 11948-11960.

18. Wu S, Suzuki Y, Ejiri Y, Noda T, Bai H, et al. (2003) Bone marrow stromal cells enhance differentiation of cocultured neurosphere cells and promote regeneration of injured spinal cord. J Neurosci Res 72: 343-351.

19. Ziv Y, Avidan H, Pluchino S, Martino G, Schwartz M (2006) Synergy between immune cells and adult neural stem/progenitor cells promotes functional recovery from spinal cord injury. Proc Natl Acad Sci U S A 103: 13174-13179.

20. Parr AM, Tator $\mathrm{CH}$, Keating A (2007) Bone marrow-derived mesenchymal stromal cells for the repair of central nervous system injury. Bone Marrow Transplant 40: 609-619.

21. Coutts M, Keirstead HS (2008) Stem cells for the treatment of spinal cord injury. Exp Neurol 209: 368-377.

22. Norrving B, Kissela B (2013) The global burden of stroke and need for a continuum of care. Neurology 80: S5-12.

23. Truelsen T, Heuschmann PU, Bonita R, Arjundas G, Dalal P, et al. (2007) Standard method for developing stroke registers in low-income and middle-income countries: experiences from a feasibility study of a stepwise approach to stroke surveillance (STEPS Stroke). Lancet Neurol 6: 134-139.

24. Donnan GA, Fisher M, Macleod M, Davis SM (2008) Stroke. Lancet 371: 1612-1623.

25. Brandstater ME (1999) Stroke rehabilitation. In: DeLisa JA, Gans BM, editor. Rehabilitation Medicine. (3rdedn) Phildelphia: Lippincott- Raven Publishers.

26. Reynolds BA, Weiss S (1992) Generation of neurons and astrocytes from isolated cells of the adult mammalian central nervous system. Science 255: 1707-1710.

27. Bang OY, Lee JS, Lee PH, Lee G (2005) Autologous mesenchymal stem cell transplantation in stroke patients. Ann Neurol 57: 874-882.

28. Chang YC, Shyu WC, Lin SZ, Li H (2007) Regenerative therapy for stroke. Cell Transplant 16: 171-181. 
29. Chopp M, Li Y (2002) Treatment of neural injury with marrow stromal cells. Lancet Neurol 1: 92-100.

30. Kondziolka D, Steinberg GK, Wechsler L, Meltzer CC, Elder E, et al. (2005) Neurotransplantation for patients with subcortical motor stroke: a phase 2 randomized trial. J Neurosurg 103: 38-45.

31. Tang Y, Yasuhara T, Hara K, Matsukawa N, Maki M, et al. (2007) Transplantation of bone marrow-derived stem cells: a promising therapy for stroke. Cell Transplant 16: 159-169.

32. Roh JK, Jung KH, Chu K (2008) Adult stem cell transplantation in stroke: its limitations and prospects. Curr Stem Cell Res Ther 3: 185-196.

33. Schäbitz WR, Kollmar R, Schwaninger M, Juettler E, Bardutzky J, et al. (2003) Neuroprotective effect of granulocyte colony-stimulating factor after focal cerebral ischemia. Stroke 34: 745-751.

34. Shyu WC, Lin SZ, Chiang MF, Su CY, Li H (2006) Intracerebral peripheral blood stem cell (CD34+) implantation induces neuroplasticity by enhancing beta 1 integrin-mediated angiogenesis in chronic stroke rats. J Neurosci 26: 3444-3453.

35. Shen LH, Li Y, Chen J, Zhang J, Vanguri P, et al. (2006) Intracarotid transplantation of bone marrow stromal cells increases axon-myelin remodeling after stroke. Neuroscience 137: 393-399.

36. Reeve A, Simcox E2, Turnbull D3 (2014) Ageing and Parkinson's disease: why is advancing age the biggest risk factor? Ageing Res Rev 14: 19-30.

37. Beitz JM (2014) Parkinson's disease: a review. Front Biosci 1: 65-74.

38. Kulisevsky J, Luquin MR, Arbelo JM, Burguera JA, Carrillo F, et al. (2013) Advanced Parkinson's disease: clinical characteristics and treatment. Part II. Neurologia 28: 558-583.

39. Lindvall O, Björklund A (2004) Cell therapy in Parkinson's disease NeuroRx 1: 382-393.

40. Lindvall O, Brundin P, Widner H, Rehncrona S, Gustavii B, et al. (1990) Grafts of fetal dopamine neurons survive and improve motor function in Parkinson's disease. Science 247: 574-577.

41. Armstrong RJ, Tyers P, Jain M, Richards A, Dunnett SB, et al. (2003) Transplantation of expanded neural precursor cells from the developing pig ventral mesencephalon in a rat model of Parkinson's disease. Exp Brain Res 151: 204-217.

42. Ourednik J, Ourednik V, Snyder EY (2002) Fetal neural tissue and stem cell grafts may induce plasticity in damaged mammalian brain.Clin Neuroscience Res 2: 80-85.

43. Kim JH, Auerbach JM, Rodríguez-Gómez JA, Velasco I, Gavin D, et al. (2002) Dopamine neurons derived from embryonic stem cells function in an animal model of Parkinson's disease. Nature 418: 50-56.

44. Dasari VR, Spomar DG, Cady C, Gujrati M, Rao JS, et al. (2007) Mesenchymal stem cells from rat bone marrow downregulate caspase-3mediated apoptotic pathway after spinal cord injury in rats. Neurochem Res 32: 2080-2093.

45. Murrell W, Wetzig A, Donnellan M, Féron F, Burne T, et al. (2008) Olfactory mucosa is a potential source for autologous stem cell therapy for Parkinson's disease. Stem Cells 26: 2183-2192.

46. Eisen A (2009) Amyotrophic lateral sclerosis: A 40-year personal perspective. J Clin Neurosci 16: 505-512.

47. Henkel JS, Engelhardt JI, Siklós L, Simpson EP, Kim SH, et al. (2004) Presence of dendritic cells, MCP-1, and activated microglia/macrophages in amyotrophic lateral sclerosis spinal cord tissue. Ann Neurol 55: 221-235.

48. Bruijn LI, Miller TM, Cleveland DW (2004) Unraveling the mechanisms involved in motor neuron degeneration in ALS. Annu Rev Neurosci 27: 723-749.

49. Miller RG, Mitchell JD, Moore DH (2012) Riluzole for amyotrophic lateral sclerosis (ALS)/motor neuron disease (MND). Cochrane Database Syst Rev 3: CD001447.

50. Ferrero I, Mazzini L, Rustichelli D, Gunetti M, Mareschi K, et al. (2008) Bone marrow mesenchymal stem cells from healthy donors and sporadic amyotrophic lateral sclerosis patients. Cell Transplant 17: 255-266.
51. Gordon PH (2013) Amyotrophic Lateral Sclerosis: An update for 2013 Clinical Features, Pathophysiology, Management and Therapeutic Trials. Aging Dis 4: 295-310.

52. Mazzini L, Mareschi K, Ferrero I, Vassallo E, Oliveri G, et al. (2008) Stem cell treatment in Amyotrophic Lateral Sclerosis. J Neurol Sci 265: 78-83.

53. Dimos JT, Rodolfa KT, Niakan KK, Weisenthal LM, Mitsumoto H, et al. (2008) Induced pluripotent stem cells generated from patients with ALS can be differentiated into motor neurons. Science 321: 1218-1221.

54. Ropper AH, Brown RH (2006) Adams and Victor's Principles of Neurology. (8thedn), Günes Kitabevi, Ankara.

55. Miller AE, Lublin FD, Coyle PK (2003) Pathology, pathogenesis, and pathophysiology. Multipl Sclerosis in Clinical Practice, Martin Dunitz, London.

56. Nielsen NM, Westergaard T, Rostgaard K, Frisch M, Hjalgrim H, et al. (2005) Familial risk of multiple sclerosis: a nationwide cohort study. Am J Epidemiol 162: 774-778.

57. Compston A, Ebers G, Lassman H, Mcdonald I, Bryan Matthews B, et al. (1998) Symptoms and sings of multipl sclerosis. McAlpine's Multipl Sclerosis, Churchill Livingstone, London.

58. McDonald WI, Compston A, Edan G, Goodkin D, Hartung HP, et al. (2001) Recommended diagnostic criteria for multiple sclerosis: guidelines from the International Panel on the diagnosis of multiple sclerosis. Ann Neurol 50: 121-127.

59. Blanco Y, Saiz A, Carreras E, Graus F (2005) Autologous haematopoieticstem-cell transplantation for multiple sclerosis. Lancet Neurol 4: 54-63.

60. Burt RK, Cohen B, Rose J, Petersen F, Oyama Y, et al. (2005) Hematopoietic stem cell transplantation for multiple sclerosis. Arch Neurol 62: 860-864.

61. Novik AA, Ionova TI, Bisaga GN, Kishtovich AV, Fedorenko DA, et al. (2005) Clinical and quality of life responses to high-dose chemotherapy plus autologous stem cell transplantation in patients with multiple sclerosis: two case reports. Cytotherapy 7:363-367.

62. Papadaki HA, Tsagournisakis M, Mastorodemos V, Pontikoglou C, Damianaki A, et al. (2005) Normal bone marrow hematopoietic stem cell reserves and normal stromal cell function support the use of autologous stem cell transplantation in patients with multiple sclerosis. Bone Marrow Transplant 36: 1053-1063.

63. Uccelli A, Zappia E, Benvenuto F, Frassoni F, Mancardi G (2006) Stem cells in inflammatory demyelinating disorders: a dual role for immunosuppression and neuroprotection. Expert Opin Biol Ther 6: 17-22.

64. Egemen idiman (2013) Multiple Skleroz tani ve tedavi klavuzu kitabi. Galenos yayinevi.

65. Hess DC, Borlongan CV (2008) Stem cells and neurological diseases. Cell Prolif 41 Suppl 1: 94-114.

66. Santiago Grisolía J (2001) Stem cell grafting for epilepsy: clinical promise and ethical concerns. Epilepsy Behav 2: 318-323.

67. Harting MT, Baumgartner JE, Worth LL, Ewing-Cobbs L, Gee AP, et al. (2008) Cell therapies for traumatic brain injury. Neurosurg Focus 24: E18.

68. Oliveira AA Jr, Hodges HM (2005) Alzheimer's disease and neural transplantation as prospective cell therapy. Curr Alzheimer Res 2: 79-95.

69. Schouten JW, Fulp CT, Royo NC, Saatman KE, Watson DJ, et al. (2004) A review and rationale for the use of cellular transplantation as a therapeutic strategy for traumatic brain injury. J Neurotrauma 21: 1501-1538.

70. Shenaq SM, Bullocks JM, Dhillon G, Lee RT, Laurent JP (2005) Management of infant brachial plexus injuries. Clin Plast Surg 32: 79-98, ix.

71. Sugaya K (2005) Possible use of autologous stem cell therapies for Alzheimer's disease. Curr Alzheimer Res 2: 367-376.

72. Attar A, Ayten M, Ozdemir M, Ozgencil E, Bozkurt M, et al. (2011) An attempt to treat patients who have injured spinal cords with intralesional implantation of concentrated autologous bone marrow cells. Cytotherapy 13: $54-60$. 
Citation: Kocaoglu M, Korucu M, Civlan S, Ozdemir K, Ozdemir M, et al. (2014) Stem Cell Therapy in the Treatment of Neurological Diseases. Brain Disord Ther 3: 132. doi:10.4172/2168-975X.1000132 